\title{
Assessment of Contributions of Community Tuberculosis Intervention to Tuberculosis Case Detection and Treatment Outcome in Two States in Nigeria
}

\author{
Audu Onyemocho' ${ }^{*}$, Hassan Abiodun2, Queen Ogbuji², Adewale Osho ${ }^{2}$, Shember-Agela Igbabul ${ }^{3}$, \\ Gajere Julius $^{4}$, Omole Victoria Nanben', Anejo-Okopi Joseph ${ }^{6}$ \\ ${ }^{1}$ Department of Epidemiology and Community Health, College of Health Sciences, Benue State University, Makurdi, Benue State, \\ Nigeria \\ ${ }^{2}$ Association for Reproductive and Family Health, Abuja, Nigeria \\ ${ }^{3}$ Benue State Epidemiology and Disease Control Unit, Makurdi, Benue State, Nigeria \\ ${ }^{4}$ Ministry of Health, Kaduna state, Kaduna, Nigeria \\ ${ }^{5}$ Department of Community Medicine, College of Medicine, Kaduna State University, Kaduna, Nigeria \\ ${ }^{6}$ Department of Microbiology, Faculty of Natural Sciences, University of Jos, Plateau State, Nigeria \\ Email: *audeeony@yahoo.com
}

How to cite this paper: Onyemocho, A., Abiodun, H., Ogbuji, Q., Osho, A., Igbabul, S.-A., Julius, G., Nanben, O.V. and Joseph, A.-O. (2020) Assessment of Contributions of Community Tuberculosis Intervention to Tuberculosis Case Detection and Treatment Outcome in Two States in Nigeria. Journal of Tuberculosis Research, 8, 136-147. https://doi.org/10.4236/jtr.2020.83012

Received: January 21, 2020

Accepted: August 14, 2020

Published: August 17, 2020

Copyright $\odot 2020$ by author(s) and Scientific Research Publishing Inc. This work is licensed under the Creative Commons Attribution International License (CC BY 4.0).

http://creativecommons.org/licenses/by/4.0/ (c) (i) Open Access

\begin{abstract}
Background: Nigeria, one of the high burden Tuberculosis countries, has developed various intervention strategies to ensuring universal access to quality-assured tuberculosis diagnosis and treatment. However, low case detection and unsuccessful treatment outcome still remains a serious challenge in most states. Community Tuberculosis care was born against this background in 2010 as a complementing front to combat the challenges, bringing directly observed treatment short-course strategy beyond the clinic settings to the door steps of patients. This study evaluates the contributions of the intervention to Tuberculosis case detection and treatment outcomes in two states in Nigeria. Materials and Method: A retrospective study with multistage sampling technique was employed to review 23,241 presumptive Tuberculosis cases enrolled for management between 2014-2017. Chi-square $\left(\chi^{2}\right)$ test was used for test of association between the independent variables and the main outcomes of the study, with statistical significance set at p-value of 5\%. Results: The annual percentage increase for both states was $24.7 \%, 189.8 \%$ and $114.5 \%$ in the study group as against $5.2 \%, 44.6 \%$ and $65.6 \%$ in control group. Overall, $23.8 \%$ were bacteriologically positive (either AFB or Gene-Xpert $\mathrm{MTB} /$ Rif) and $1.4 \%$ were clinically evaluated to be positive, while $74.8 \%$ were bacteriologically negative. Of the total 5861 cases treated, successful treatment
\end{abstract}


rate of the patients in the study group was $88.6 \%$ as compared to $76.1 \%$ in the control group. The relationship between the referral system from communities where the intervention program was implemented and the case detection/treatment outcome was statistically significant (OR 95\% CI = 3.15, 2.95 3.35). Conclusion: The community level Tuberculosis intervention led to significantly better case detection and treatment outcome when compared to the conventional approach ( $\mathrm{p} \leq 0.05$ ). Therefore, full community engagement should be advocated as a major strategy for End Tuberculosis planed by WHO since the patients are found in the community and not in the health facilities.

\section{Keywords}

Case Detection, Community Care, Contribution, Tuberculosis, Treatment Outcome

\section{Introduction}

Tuberculosis (TB) was declared as global health emergency in 1993, but it still remains one of the world's deadliest infectious diseases [1] [2] [3]. In 2015, the burden of TB was the highest in Asia and Africa with the African region bearing $24 \%$ of the World's TB burden and the highest rates of cases and deaths per capita. Of the estimated 10.4 million new cases of TB in the same year, $11.0 \%(1.2$ million) were co-infected with $\mathrm{HIV}$ and 1.5 million people died from $\mathrm{TB}$, including almost one million deaths among HIV-negative individuals and 0.4 million among people who were HIV-positive [4]. Nigeria was ranked the world's $4^{\text {th }}$ highest and the highest in Africa, with a TB incidence of 586/100,000 inhabitants [4].

Nigeria started the implementation of Directly Observed Treatment Short course (DOTS) strategy in 1993 and achieved a 100\% state coverage in 2003, but over there after the accessibility to the DOTS services remains sub-optimal. This was worse among the rural dwellers, most of who are poor and live several kilometres from the DOTS centre [5]. Community Tuberculosis Care (CTBC) was born against this background in 2010, bringing DOTS strategy beyond the clinic settings to the door steps of patients as a complementing front to combat the challenges of TB and in line with the STOP TB approach of 2005 [6]. The CTBC was aimed at demand creation through health education, social mobilization and awareness campaign by trained community volunteers and community based organizations. By the end of 2014, there were over 5300 TB service points and 1602 Microscopy centres distributed across the entire country [7]. Despite the achievement, the national and states case detection rate still remain low. For instance, the national and Benue State case detection rate stands at $17 \%$ and $15 \%$ respectively [8] [9]. These values are short of the World Health Organization (WHO) target of $70 \%$ and treatment target of $85 \%$ [9]. Therefore, low TB case 
findings remain the biggest problem of TB control efforts in Nigeria with Nigeria still accounting for $15 \%$ (about half a million people) of the globally estimated 3.3 million missing TB cases that were either not diagnosed or diagnosed but not reported [10].

In 2015, the need for more TB service delivery points was looked into and that led to the implementation of another approach of community-based intervention program called the Active Case Finding (ACF). The ACF approached targeted the most at risk groups (e.g., Persons Living with HIV (PLHIV), slum dwellers, diabetics, migrants/internally displaced persons, nomadic populations, and prisoners). A total of 365 intervention sites across twenty prioritized TB states were identified for the project and volunteers from those communities were trained as Community Tuberculosis Workers (CTWs). Each CTW was expected to reach an average of twenty households per week. The immediate result of their activities was to increase demand creaction of TB services through social and behavior communication strategy, community outreaches and referral linkages as well as contributing to TB case notification and TB management outcome in Nigeria [11]. The purpose of this study is to evaluate the contributions of these community interventions (CTBC and $\mathrm{ACF}$ ) to $\mathrm{TB}$ case detection and treatment outcomes in two states in Nigeria.

\section{Materials and Method}

\subsection{Study Setting}

Our study was conducted in Benue and Kaduna States, Nigeria. What informed the decision for the States selection was the research questions which was aimed at assessing the outcome variables of the study (case detection and the treatment outcome). The two states are from different geo-political zones but they share common socio-demographic characteristics in terms of religion, culture, education and life style. Both States have 23 local government areas each, and the indigenes are mostly farmers. The TB control programs in the two States are supported by Netherlands Leprosy Relief (NLR) from inception till date. In addition, the two States were among the States of the Federation that had benefited from the CTBC and ACF which were commenced in 2010 and 2015 respectively.

Benue State is located in the North Central Geographic zone of Nigeria and is bordered by Nasarawa, Taraba, Ebonyi, Kogi, and Enugu States. The State has an estimated population of 5,840,420 in 2017 (i.e. 3.0\% projection from $2006 \mathrm{Na}$ tional population figures of 4,253,641) [12]. TB DOTS program in Benue State started in 2001 as a pilot project in four LGAs (Gwer, Otukpo, Logo and Ohimini). Over the years the program achieved 100\% DOTS coverage in all the LGAs using the WHO set standard of one DOTS centre per 25,000 populations. The CTBC intervention in Benue State commenced in 2010 with 10 LGAs (Otukpo, Oju, Kwande, Katsina-Ala, Ushongo, Vandekiya, Makurdi, Ukum, Gboko, and Konshisha). Active case finding using house-to-house approach was implemented in two slums across two LGAs in 2015. These LGAs were Ushongo and 
Gboko [13].

Kaduna State is located in the north western zone of Nigeria and it covers an area of 46,053 square kilometres. The State shares boundaries with Niger State to the west, Zamfara, Katsina and Kano States to the north, Bauchi and Plateau States to the east and FCT Abuja and Nasarawa State to the south. The State projected population for 2017 was 8,397,541 (i.e. 3.0\% projection from $2006 \mathrm{Na}$ tional population figures of 6,113,503) [12]. The Kaduna State Tuberculosis and Leprosy Control Program (KDTBLCP) were established in 1997 following the signing of the first memorandum of understanding (MOU) with the NLR. The СTBC intervention in Kaduna State was implemented in 2010 with 10 LGAs (Chukun, Igabi, Jamaa, Giwa, Kaduna North, Kaduna South, Lere, Sabon-Gari, Zango Kataf and Zaria), while the ACF was implemented in ten slums across six LGAs in 2015. These LGAs were Kaduna North, Chikun, Zaria, Kaduna South, Sabon Gari and Jamma. Prior to the implementation of the CTBC intervention programs, the annual TB case notification rate of Benue and Kaduna States was below the national target of $85 \%$. According to the Epi-analysis report of 2014, the annual case notification rate of Benue was above 35 per 100,000 as against less than 25 per 100,000 reported for Kaduna State [14].

\subsection{Study Design}

A retrotrospective study design was employ for the study.

\subsection{Study Population}

All registered TB patients, enrolled for treatment at the DOTS centres between January 2014 and September, 2017 were used as the study population. No contact with human subjects occurred; only secondary unlinked data were used. Patients with incomplete information on source of referrals, sociodemographic variables, date of diagnosis, date of treatment and outcomes of treatment were excluded from the study.

\subsection{Sample Size}

Sixteen high TB burden facilities across the two States were selected by convenience, assuming that each facility serves the catchment population of 25,000. The selected DOTS centres were categorised into two; the facilities located within the districts where community based interventions (CTBC and ACF) was implemented were used as the study facilities while the facilities located within the districts where CTBC and ACF were not implemented were used as the control facilities. Overall, four study and four control facilities (total of eight) were selected from each State.

\subsection{Sampling Procedure}

Multistage sampling technique was used for selection of communities and facilities where the study was conducted. 


\subsubsection{Stage 1 (Selection of LGAs)}

Of the 46 LGAs, 16 were selected by convenience; 8 from Kaduna State and 8 from Benue State. Of the 8 from each state, 4 were from the study and 4 from the control groups. The key factor that informed the selection was evidence of training of CVs and CBOs in the LGAs and the communities.

\subsubsection{Stage 2 (Selection of Facilities)}

One facility was selected from each of the 16 LGAs. The selection of the facilities was done by using outlier sampling methodology; by first ranking the facilities with the highest notification data for Tuberculosis in the study and control facilities.

\subsection{Data Collection}

The data sources used in each of the selected facilities was the routine National Tuberculosis and Leprosy Control Program (NTBLCP) standardized facility reporting registers, the presumptive register, community referral register, LGA TB register, patients TB treatment cards and sputum request follow up registers. The relevant independent variables used were the age of patients, sex, disease sites and treatment category, sputum microscopy at baseline and follow up, date of diagnosis, date of commencement of anti-TB drugs, source of referral, while the outcome measures of interest were number of cases referred and treatment outcome. The TB health facility registers were provided by the facility research participants and the information seen was exported to extraction sheet. The Nigerian NTLCP guideline adopted from WHO [15], was used for case detection rate and treatment outcome definitions.

\subsection{Data Analysis}

Data that were extracted from the data sources were entered into predesigned software in Statistical Packages for Social Sciences (SPSS) version 23 (SPSS statistics for windows, version 23.0, Armonk, NY: IBM Corp). Confidence interval was calculated using open epi. Software. Frequency Tables, Charts, mean and standard deviation were used to summarize the independent variables of interest. The main outcome of the study was compared with the patient's point of care. Pearson chi-square $\left(\chi^{2}\right)$ test was used for test of association between the independent variables and the main outcome of the study, with statistical significance set at $p$-value of $5 \%$.

\subsection{Ethical Consideration and Informed Consent}

Ethical approval for the study was obtained from the Benue and Kaduna States Ministry of Health (SMoH) before the commencement of the study. Approvals from the management of the selected health facilities were also obtained.

\section{Results}

\subsection{Age and Sex Distribution of Patients}

Overall, there were 23,241 identified presumptive Tuberculosis cases reviewed; 
$14,553(62.6 \%)$ are from Kaduna State while 8688 (37.4\%) are from Benue State. The male to female ratio of the study population was $1: 1$. The age of the patients ranges from 1 - 110 years, with predominant age group of 16 - 30 years $(34.3 \%)$, followed by 31 - 45 years ( $31.2 \%)$, and the mean age was 36.4 ( \pm 16.6 years). This is shown in Table 1.

\subsection{Point of Care of Presumptive TB Patients}

Figure 1 represents the point of care of presumptive $\mathrm{TB}$ cases seen within the reviewed period (January, 2014-September, 2017). Of the total 8688 presumptive cases seen in Benue State, $82.8 \%$ accessed their care at facilities located in the community based intervention areas while the rest (17.2\%) are from the facilities located in areas where the community-based intervention was not implemented. Similarly, $74.2 \%$ and $25.8 \%$ of presumptive TB cases in Kaduna State accessed their care in the facilities located within the communities where community-based intervention was implemented and those where it was not implemented respectively. Overall, the proportion of presumptive TB cases seen at facilities in the communities were community-based intervention was implemented was about 3.15 times higher than cases seen in the communities were the intervention were not implemented (OR 95\% CI = 3.15, 2.95 - 3.35).

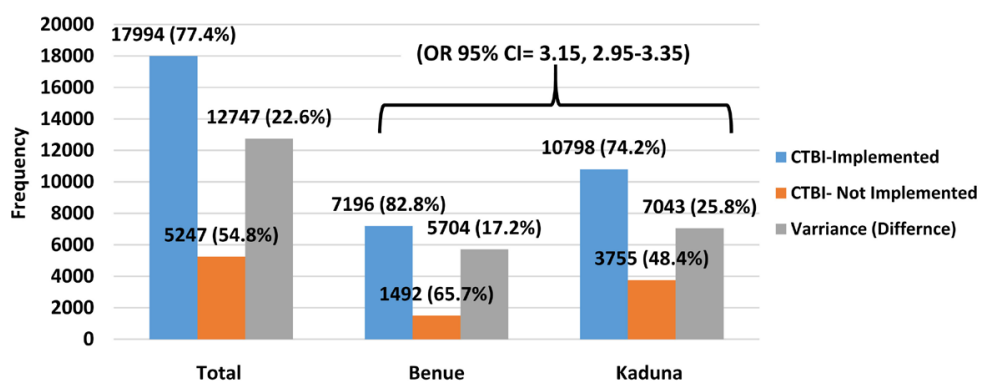

Figure 1. Presumptive TB cases by point of care. Key: CTBI = Community-Based Tuberculosis Intervention.

Table 1. Age and sex distribution of presumptive TB cases by states (2014-2017).

\begin{tabular}{cccc}
\hline Age/Sex & $\begin{array}{c}\text { Benue State } \\
(\mathbf{n}=\mathbf{8 6 8 8})\end{array}$ & $\begin{array}{c}\text { Kaduna State } \\
(\mathbf{n}=\mathbf{1 4}, \mathbf{5 5 3})\end{array}$ & $\begin{array}{c}\text { Total } \\
(\mathbf{n}=\mathbf{2 3 , 2 4 1 )}\end{array}$ \\
\hline Age Group (Years) & Frequency (\%) & Frequency (\%) & Frequency (\%) \\
$1-15$ & $855(9.8)$ & $1122(7.7)$ & $1977(8.5)$ \\
$16-30$ & $2518(29.0)$ & $5458(37.5)$ & $7976(34.3)$ \\
$31-45$ & $2717(31.3)$ & $4537(31.2)$ & $7254(31.2)$ \\
$46-60$ & $1688(19.4)$ & $2370(16.3)$ & $4058(17.5)$ \\
$61-75$ & $741(8.5)$ & $857(5.9)$ & $1598(6.9)$ \\
$78-90$ & $163(1.9)$ & $193(1.3)$ & $356(1.5)$ \\
$\geq 91$ & $6(0.1)$ & $16(0.1)$ & $22(0.1)$ \\
Sex & & & $11,626(50.0)$ \\
Male & $4317(49.7)$ & $7309(50.2)$ & $11,615(50.0)$ \\
Female & $4371(50.3)$ & $7244(49.8)$ & \\
\hline
\end{tabular}

Mean age $=36.4( \pm 16.6)$ Years. 


\subsection{Trend of Presumptive TB Cases}

The yearly trend of the presumptive TB cases reviewed is shown in Figure 2. The annual percentage increase for both States put together was $24.7 \%, 189.8 \%$ and $114.5 \%$ in areas where community-based intervention was implemented as against $5.2 \%, 44.6 \%$ and $65.6 \%$ in areas where the intervention was not implemented (2015, 2016 and 2017 respectively). The variance was statistically significant $\left(X^{2}=231.751 ; \mathrm{df}=1 ; \mathrm{P}\right.$-value $\left.=0.000\right)$.

\subsection{Trend of Positive Testing Rates}

Of the total 23,241 presumptive TB cases tested, 5539 (23.8\%) were bacteriologically positive (either AFB or Gene-Xpert MTB/Rif) and 322 (1.4\%) were clinically evaluated to be positive, while $17,380(74.8 \%)$ were bacteriologically negative. These corresponds to overall positive rate of 5861 (25.2\%). While the DOTS facilities located within the communities where community-based intervention program experienced a consistent increase in positive rates over the years, the facilities within the communities where the program was not implemented had inconsistent positive rates. The relationship between the community-based $\mathrm{TB}$ intervention and the yearly positive testing rates was statistically significant $\left(\chi^{2}=\right.$ 155.9; $\mathrm{df}=9 ; \mathrm{p} \leq 0.05$ ) (Figure 3 ).

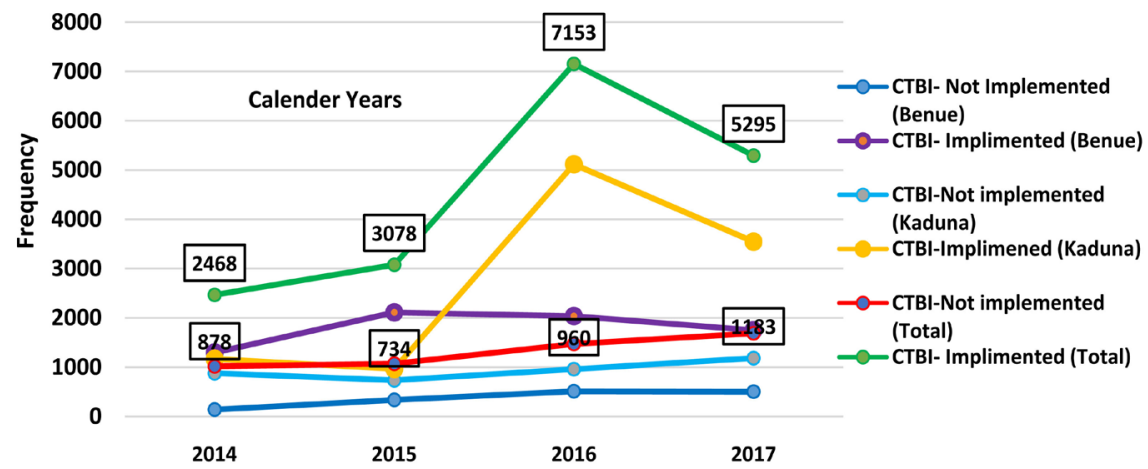

Figure 2. Trend of presumptive TB cases by intervention status (Jan. 2014-Sep. 2017). Key: CTBI $=$ Community-based Tuberculosis Intervention.

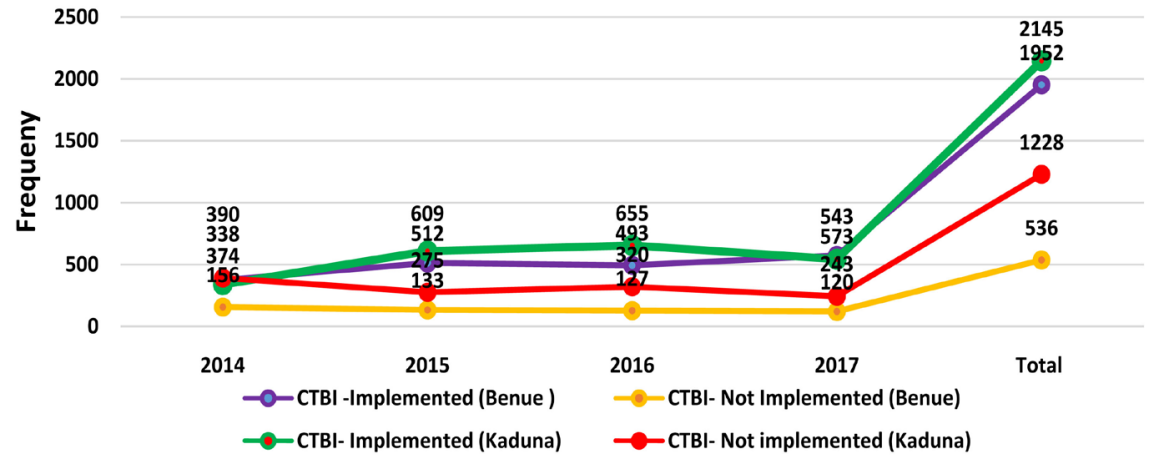

Figure 3. Trend of positive testing rates in states by intervention status. CTBI $=$ Community-based TB Intervention. 


\subsection{Disease Site and Type of Patient}

Extra-pulmonary $\mathrm{TB}$ constitutes $5.5 \%(\mathrm{n}=322)$ of the total cases seen within the period, while pulmonary TB constitute $94.5 \%(\mathrm{n}=5539)$. More than four-fifth $(93.0 \%)$ of the patients were new cases. Other category of patients seen were relapse (3.6\%), treatment after loss to follow up $(0.8 \%)$, return after default $(0.4 \%)$, transferred in $(0.2 \%)$, unknown previous history $(0.2 \%)$ and others (1.4\%) (Table 2$)$.

\subsection{Treatment Supporters}

Of the total 5861 patients who were treated 4097 (69.9\%) had their treatment with engagement of treatment supporters, while 1764 (30.1\%) had their treatment without treatment supporters. Among the patients who had treatment supporters, $79.1 \%(\mathrm{n}=3242)$ are from facilities where the community-based intervention program was implemented (46.3\% in Kaduna state and $32.8 \%$ in Benue state respectively). Of the 1764 who did not have treatment supporters, 909 (51.5\%) are from facilities where the intervention was not implemented (30.0\% in Kaduna state and $21.5 \%$ in Benue state respectively). The difference in the involvement of treatment supporters by intervention status was statistically significant $(\mathrm{P}<0.05)$ (Table 3$)$.

\subsection{Treatment Outcome}

Of the total 5861 cases treated, $84.8 \%$ had successful outcome (52.2\% cured and $32.6 \%$ treatment completed), $5.0 \%$ had treatment failure, $4.9 \%$ died and $2.9 \%$ loss to follow up. The successful treatment rate of the patients in the community where the CTB-intervention was implemented was $88.6 \%$ (58.4\% cured and $30.2 \%$ treatment completed) as compared to $76.1 \%$ (37.8\% cured and $38.3 \%$ treatment completed) in the communities where intervention did not take place. Treatment failure and death was higher amongst the patients treated in community where the CTB-intervention was not implemented $(8.4 \%$ and $4.8 \%)$ as

Table 2. Type of patient.

\begin{tabular}{ccc}
\hline Variables & Frequency & Percent \\
\hline Disease site & 5539 & \\
Pulmonary & 322 & 94.5 \\
Extra-pulmonary & 5861 & 5.5 \\
Total & & 100.0 \\
Type of Treatment & 5448 & \\
New & 209 & 93.0 \\
Relapse & 48 & 3.6 \\
Return after default & 27 & 0.8 \\
Treatment after failure & 26 & 0.5 \\
Transferred in & 14 & 0.4 \\
Unknown previous history & 9 & 0.2 \\
Others & 80 & 0.2 \\
Total & 5861 & 1.4 \\
\hline
\end{tabular}


Table 3. Engagement of treatment supporters by intervention status.

\begin{tabular}{|c|c|c|c|c|c|c|c|}
\hline \multirow{2}{*}{ State } & \multirow{2}{*}{ СТВC } & \multicolumn{2}{|c|}{ Treatment Supporter } & \multirow{2}{*}{ Total } & \multicolumn{3}{|c|}{ Statistical values } \\
\hline & & Yes & No & & $X^{2}$ & $\mathrm{df}$ & p-value \\
\hline \multirow{2}{*}{ Benue } & Implemented & $1345(32.8)$ & $607(34.4)$ & $1952(33.3)$ & & & \\
\hline & Not-implemented & $156(3.8)$ & $380(21.5$ & $536(9.1)$ & & & \\
\hline \multirow{3}{*}{ Kaduna } & Implemented & $1897(46.3)$ & $248(14.1)$ & $2145(36.6)$ & & & \\
\hline & Not-implemented & $699(17.1)$ & $529(30.0)$ & $1228(21.0)$ & & & \\
\hline & Total & $4097(100.0)$ & $1764(100.0)$ & $5861(100.0)$ & 879.9 & 3 & 0.0000 \\
\hline
\end{tabular}

Table 4. Tuberculosis treatment outcome by community-based TB intervention status.

\begin{tabular}{cccc}
\hline \multirow{2}{*}{ Treatment outcome } & \multicolumn{3}{c}{ CTBI Status } \\
\cline { 2 - 4 } & $\begin{array}{c}\text { Implemented } \\
\mathrm{n}(\%)\end{array}$ & $\begin{array}{c}\text { Not implemented } \\
\mathrm{n}(\%)\end{array}$ & $\begin{array}{c}\text { Total } \\
\mathrm{n}(\%)\end{array}$ \\
\hline Cured & $2389(58.4)$ & $669(37.8)$ & $3058(52.2)$ \\
Treatment Completed & $1235(30.2)$ & $678(38.3)$ & $1913(32.6)$ \\
Treatment Failed & $143(3.5)$ & $149(8.4)$ & $292(5.0)$ \\
Died & $160(3.9)$ & $127(7.2)$ & $287(4.9)$ \\
Loss of Follow Up & $86(2.1)$ & $85(4.8)$ & $171(2.9)$ \\
Not Evaluated & $78(1.9)$ & $62(3.5)$ & $140(2.4)$ \\
Total & $4091(100.0)$ & $1770(100.0)$ & $5861(100.0)$ \\
& $\chi^{2} \mathbf{2 5 6 . 4 ; ~} \mathbf{d f}=\mathbf{5}$; P-value $=\mathbf{0 . 0 0 0 0}$ &
\end{tabular}

compared to community where the CTB-intervention was implemented (3.5\% and 3.9\%). The relationship between the CTB-intervention status and the treatment outcome was statistically significant (P-value $\leq 0.05$ ) (Table 4).

\section{Discussion}

One of the major aims of a TB control programme is to notify as many cases as possible. Implementing the community intervention strategy is believed to be a key approach to enhancing good referral cascade system between the community and the health facilities. The strategy was evaluated to gain a better understanding of the impact of the intervention and to provide scientific basis for any modification of community-based TB intervention strategies in Nigeria. The existence of presumptive and diagnosed TB cases seen in our study attest to the fact that TB is still an issue of public health importance and the socio-demographic characteristics of the patients in this study (Table 1) is consistent with the documented global epidemiology of tuberculosis [16] [17] [18] [19] [20].

In our study, we observed a progressive increase in the proportion of presumptive TB cases between 2015 to 2017. The increase recorded in the communities where the program was implemented was far above the $85 \%$ national target while that of the communities where the intervention was not imple- 
mented was below the national average. The findings from our study therefore, indicates that the community based intervention program created good opportunities for the identification of presumptive TB cases among the people who do not actively seek for care on their own. Despite the gradual increase over the years, there was a decline in the reported number of presumptive cases in 2017 in our study. Much of this decrease probably reflects challenges in terms of the commitment of community health workers to the project. Therefore, this decrease calls for bottleneck analysis.

As previously documented in other studies, $23.8 \%$ of the total presumptive TB cases in our study were bacteriologically positive and only $1.4 \%$ of the patients treated were clinically evaluated to be positive. Our study indicates that most of the infection of the patients in Benue and Kaduna States, Nigeria are pulmonary TB (Table 2). This finding is also in line with the WHO report of the sites of TB. Therefore, it could be indirectly said that the risk of TB infection in Benue and Kaduna States remains high.

Regarding the positive testing rate, $23.8 \%$ of the total presumptive TB cases in our study were bacteriologically positive and only $1.4 \%$ of the patients treated were clinically evaluated to be positive. About $73.6 \%$ of the patients who received their drugs in the communities where CTBC were implemented engaged the services of treatment supporters, whom were either family members, community volunteers, facility staff or civil society organization.

Also in this study, majority of patients who were treated in communities where community TB intervention was implemented had more successful treatment outcome compared to the patients who had their treatment in facilities where community TB intervention was not implemented. This implies that in addition to case detection rate the program which is a modified model of Community intervention may be more feasible and effective for TB case detection and treatment as community workers are familiar with the layout of the community and have community member's trust which healthcare officials would have to develop. Moreover, a community-based approach like this helps to empower each community to deal with its own problems and also provides patient with a greater degree of autonomy and satisfaction with the treatment regime.

\section{Conclusion}

The findings show that the community level intervention has improved the TB case findings and treatment outcome among the patients in Benue and Kaduna States Nigeria. Hence, the program should be sustained and be extended to all the LGAs and States of the federation.

\section{Study Limitations}

Some limitations of our analysis should be kept in mind. As our data consisted only of secondary unlinked data; no contact with human subjects occurred. We 
cannot exclude the possibility of poor recording and reporting systems. However, this has been reduced via several recording and reporting training and re-training organized by the State TB and leprosy control programme for staff working in the public and private health sectors.

\section{Acknowledgements}

This study was funded by Association for Family and Reproductive Health (AFRH Abuja), in collaboration with the Global Fund. Our appreciation also goes to the Benue and Kaduna States TB management team who facilitated access to the selected facilities and for making the required registers available. The rigorous activities of the research assistance throughout the period of the fieldwork are also appreciated.

\section{Conflicts of Interest}

The authors declare no conflicts of interest regarding the publication of this paper.

\section{References}

[1] WHO (1994) Global Tuberculosis Program. TB: A Global Emergency, WHO Report on the TB Epidemic. World Health Organization, Geneval. https://apps.who.int/iris/handle/10665/58749

[2] Ruvandhi, R.N. and Jon, S.F. (2015) A Tale of Two Global Emergencies: Tuberculosis Control Efforts Can Learn from the Ebola Outbreak. European Respiratory Journal, 46, 293-296. https://erj.ersjournals.com https://doi.org/10.1183/13993003.00436-2015

[3] Grange, J.M. and Zumla, A. (2002) The Global Emergency of Tuberculosis: What Is the Cause? Journal of the Royal Society for the Promotion of Health, 122, 78. https://doi.org/10.1177/146642400212200206

[4] WHO (2015) Global Tuberculosis Report.

[5] FMOH (2007) Guidelines for Implementing Community Tuberculosis Care in Nigeria. Federal Ministry of Health, National Tuberculosis and Leprosy Control Program, Abuja.

[6] Kingsley, U., Isaac, A., Ngozi, I., Chijioke, O. and Chika, I. (2011) From DOTS to the Stop TB Strategy: DOTS Coverage and Trend of Tuberculosis Notification in Ebonyi, South-Eastern Nigeria, 1998-2009. The Pan African Medical Journal, 9, 12. https://doi.org/10.4314/pamj.v9i1.71187

[7] Ofor, M.O. and Ofole, M.N. (2014) The Millennium Development Goals in Nigeria: An Assessment of the Journey So Far. Researcher, 6, 81-90.

[8] NTLCP (2015) Annual Report.

[9] MSH (2015) Challenge Tuberculosis. A New Worldwide Tuberculosis Project Report.

[10] FMOH Department of Public Health (2010) National Tuberculosis and Leprosy Control Program. Workers Manual, Revised 5th Edition.

[11] Kusimo, O.C., et al. (2018) Implementation of the Active TB Case Finding in Nigeria; Processes, Lessons Learnt and Recommendations. Journal of Tuberculosis Re- 
search, 6, 10-18. https://doi.org/10.4236/jtr.2018.61002

[12] National Bureau of Statistics (2017) Demographic Statistics Bulletin.

[13] MOH (2016) Benue State, Nigeria, TB Report.

[14] Babis Sismanidis WHO (2014) Epidemiological Review of Tuberculosi Disease in Nigeria.

[15] WHO (2013) Systematic Screening for Active Tuberculosis: Principles and Recommendations. WHO, Geneva, WHO/HTM/TB/2013.

http://www.who.int/tb/publications/tbscreening

[16] FMOH Nigeria, Department of Public Health (2010) National Tuberculosis and Leprosy Control Program. Revised 5th Edition, Workers Manual.

[17] WHO (2013) Systematic Screening for Active Tuberculosis: Principles and Recommendations. WHO, Geneva, WHO/HTM/TB/2013.

http://www.who.int/tb/publications/tbscreening

[18] WHO (2015) Global Tuberculosis Control Report. 20th Edition, WHO, Geneva.

[19] United State Embassy in Nigeria (2012) Nigeria Tuberculosis Fact Sheet. http://nigeria.usembassy.gov/

[20] WHO (2013) Global Tuberculosis Report, 2013. WHO, Geneva. 